\title{
Further guidance for REDD+ safeguard information systems? An analysis of positions in the UNFCCC negotiations
}

\author{
Mary Menton', Clare Ferguson', Roosa Leimu-Brown', Stephen Leonard², Maria Brockhaus², \\ Amy E Duchelle² and Christopher Martius ${ }^{2}$
}

\section{Key points}

We analyzed submissions to the Subsidiary Body for Scientific and Technological Advice (SBSTA) from Parties and Observer Organizations on two issues: (i) party and observer positions on inclusion of further guidance on REDD+ safeguard information systems (SIS); and (ii) developing country Party experiences and lessons learned from SIS development. We also carried out a brief survey among REDD+ negotiators. The major findings are summarized as follows:

- Some Parties are against the United Nations Framework Convention on Climate Change (UNFCCC) providing further guidance on SIS, but the majority of submissions and survey respondents favor further guidance.

- Some Parties express concern about the potential trade-offs between further guidance and the promotion of country-driven approaches and national sovereignty.

- Submissions both in favor of and against further guidance emphasize the need to minimize the burden of creation of and reporting on SIS.

- While developed country Party submissions emphasize the need for SIS to demonstrate adequate governance and safeguard implementation, civil society organizations highlighted issues around equity and participation of local people in the process.

- The contrasting views suggest that a viable compromise to move the safeguarding work forward could be to produce guidance on how to develop a country-driven approach.

\section{Introduction}

Parties to the UNFCCC and civil society observers (CSOs) have expressed concern about potential negative social and environmental consequences of REDD.$+{ }^{3}$ As a result, at the Conference of the Parties (COP) in Cancun (2010), the UNFCCC agreed upon safeguards that aim to prevent such negative impacts. ${ }^{4}$ Parties will develop national-level SIS for providing

1 Solutions \& Evidence for Environment \& Development (SEED), Oxford, UK. 2 CIFOR

3 REDD+ = reducing emissions from deforestation and forest degradation, and enhancing forest carbon stocks in developing countries.

4 The Cancun Agreement (Decision 1/CP.16) listed seven REDD+ safeguards: "(a) Actions complement or are consistent with the objectives of national forest programmes and relevant international conventions and agreements; (b) Transparent and effective national forest governance structures, taking into account national legislation and sovereignty; (c) Respect for the knowledge and rights of indigenous peoples and members of local communities, by taking into account relevant international obligations, national circumstances and laws, and noting that the United Nations General Assembly has adopted the United Nations Declaration on the Rights of Indigenous Peoples; (d) The full and effective participation of relevant stakeholders, in particular, indigenous peoples and local communities, in actions referred to in paragraphs 70 and 72 of this decision; (e) Actions are consistent with the conservation of natural forests and biological diversity, ensuring that actions referred to in paragraph 70 of this decision are not used for the conversion of natural forests, but are instead used to incentivize the protection and conservation of natural forests and their ecosystem services, and to enhance other social and environmental benefits; (f) Actions to address the risks of reversals; $(\mathrm{g})$

Actions to reduce displacement of emissions." information on how REDD+ safeguards are being 'addressed and respected' and provide a summary of this information to the UNFCCC through their National Communications. Thus, safeguards will be linked to both national and international reporting systems. The Warsaw REDD+ Framework requires countries to provide the most recent SIS summary before they are eligible to receive results-based payments (RBPs). The RBPs system within the UNFCCC was further developed in October 2014, where the Green Climate Fund (GCF) Board agreed on a REDD+ RBP framework, which includes submission of SIS summary reports as a prerequisite for RBPs, but without being explicit about how the content of these reports will be assessed or followed up.

International guidance for SIS was adopted at COP 17 in Durban (2011), which requires parties to "provide information on how all [Cancun safeguards]... are being addressed and respected,"

\footnotetext{
5 Decision 12/CP.19. SIS should: (a) be consistent with the guidance identified in decision 1/CP.16, appendix I, paragraph 1;

(b) Provide transparent and consistent information that is accessible by all relevant stakeholders and updated on a regular basis; (c) Be transparent and flexible to allow for improvements over time; (d) Provide information on how all of the safeguards referred to in appendix I to decision 1/ CP.16 are being addressed and respected; (e) Be country-driven and implemented at the national level; (f) Build upon existing systems, as appropriate."
} 
but does not provide details on the types of evidence that countries might use to show this or the ways in which such evidence should be collected, verified or reported. It states that the SIS should be "country-driven" but does not clarify how this will be achieved. A number of Parties and CSOs have expressed concerns about the adequacy of this guidance (e.g. RSWG 2014). Provision of further guidance on SIS has been suggested as a key to overcoming the challenges related to developing and implementing SIS (Jagger et al. 2012); however at the country level, progress toward building national REDD+ safeguards and SIS varies (Jagger et al. 2014). Initiatives have arisen that support governments in their development of SIS and planning for implementation on the ground, for example, the Climate, Community \& Biodiversity Alliance (CCBA) and CARE International have developed the REDD+ Social and Environmental Safeguards (SES) Initiative working with national and subnational governments in 13 countries $^{6}$ and creating guidelines for a 10-step country-led process for developing SIS (REDD+SES 2012). The United Nations Collaborative Programme on Reducing Emissions from Deforestation and Forest

Degradation in Developing Countries (UN-REDD) has developed the Country Approach to Safeguards Tool (CAST) ${ }^{7}$ and made suggestions for country-led SIS (Peskett and Todd 2013).

In Durban, the UNFCCC made a formal request to the SBSTA to "consider the need for further guidance to ensure transparency, consistency, comprehensiveness and effectiveness when informing on how all safeguards are addressed and respected." The issue of further guidance for SIS was not resolved in 2012 and 2013, but will be considered by the SBSTA in Lima at COP 20.

In anticipation of the Lima meeting, the SBSTA made two calls for submissions: (i) Party and observer positions regarding inclusion of further guidance on REDD+ SIS; and (ii) developing country Party experiences and lessons learned from SIS development. In this infobrief, we analyze the submissions received by the SBSTA and the issues and concerns they raise. We also report on the results of an online survey in which we invited country delegates with experience in the UNFCCCC negotiations to respond regarding further guidance on SIS. ${ }^{8}$ In addition, we assess the treatment of safeguards in Emissions Reduction Program Idea Notes (ER-PINs) that were submitted to the Forest Carbon Partnership Facility (FCPF). Based on these data and early experiences with national-level development of SIS, described in the submissions and elsewhere, we outline the areas of convergence around the types of guidance needed and options for such guidance.

\section{Positions regarding inclusion of further guidance on REDD+ safeguards information systems}

The SBSTA received 21 submissions, 9 from Parties, 10 from CSOs and 2 from intergovernmental organizations (IGOs) (see Table 1). The Secretariat to the Convention on Biological Diversity

Table 1. Submissions to the SBSTA on safeguard information systems

\begin{tabular}{|c|c|c|c|}
\hline Submission party/observer & Abbreviation & $\begin{array}{l}\text { Signatories } \\
\text { with separate } \\
\text { submissions }\end{array}$ & $\begin{array}{l}\text { Further } \\
\text { guidance? } \\
\text { Yes / No }\end{array}$ \\
\hline \multicolumn{4}{|l|}{ Countries } \\
\hline $\begin{array}{l}\text { ASEAN (Brunei Darussalam, Cambodia, Indonesia, Lao Peoples } \\
\text { Democratic Republic, Malaysia, Myanmar, Philippines, Singapore, } \\
\text { Thailand and Vietnam) }\end{array}$ & ASEAN & Malaysia & Unclear \\
\hline Bolivia & & & Yes \\
\hline Central Africa Forests Commission & COMIFAC & & Yes \\
\hline Ecuador & & & No \\
\hline European Union & EU & & Unclear \\
\hline Malaysia & & & Unclear \\
\hline Mexico & & & No \\
\hline Norway & & & Yes \\
\hline USA & & & Unclear \\
\hline \multicolumn{4}{|l|}{ Civil Society Organizations } \\
\hline Asia Indigenous Peoples Pact & AIPP & & Yes \\
\hline Climate Action Network & CAN & & Yes \\
\hline
\end{tabular}

6 Including state- or province-level governments in Brazil, Indonesia, Peru and Mexico.

7 CAST is an Excel-based, interactive tool for countries "to plan and review the development of their approaches to REDD+ safeguards." See http://www.un-redd.org/Multiple_Benefits/CAST/tabid/133448/Default. aspx
8 An electronic invitation to participate was sent to delegates from 76 Parties. We received 18 responses, of which 6 reported to be from developed and 11 from developing countries, including 5 from least-developed countries. Ten respondents listed their country name, while the remainder chose not to disclose this information. The low response rate means that the results must be taken as supplementary information and not conclusive representations of the general trends in Party positions regarding further guidance. 
Conservation International, Environmental Defense Fund, National Wildlife Federation, Rainforest Alliance, The Nature Conservancy, Union of Concerned Scientists, World Vision International Coordinator of Indigenous Organizations of the Amazon Basin Indigenous Peoples' International Centre for Policy Research and Education

Institute for Global Environmental Strategies

REDD+ Safeguards Working Group

Transparency International

Tri-Caucus: Joint Submission by the Accra Caucus, International Indigenous Peoples' Forum on Climate Change (IIPFCC), and REDD+ Safeguards Working Group1

WWF Intergovernmental Organizations

The Center for People and Forests

Convention on Biological Diversity

\begin{tabular}{lll} 
CI-led group & Yes \\
COICA & \\
Tebtebba & Yes \\
IGES & Yes \\
RSWG & Yes \\
TI & $\begin{array}{l}\text { AIPP, COICA, } \\
\text { Tebtebba, TI }\end{array}$ & Yes \\
T-C & Yes \\
WSWG, World Vision & Yes \\
WWF & of the ACCRA caucus) \\
RECOFTC & Yes \\
CBD & & Yes \\
\hline
\end{tabular}

Commission des Forêts d'Afrique (entrale, COMIFAC) are strongly in favor, and the remaining three (EU, USA and ASEAN) imply stances in favor of further guidance without explicitly stating so. For example, the EU states that "further guidance could be supported." The civil society submissions are all strongly in favor of further guidance for SIS. The RSWG express the view that "the frequency of reporting on how safeguards are being addressed and respected is insufficient." The T-C considers that "the Cancun safeguards were only the first step" and further guidance on SIS is required to ensure safeguards are operationalized on the ground.

As illustrated in Figure 1, the survey results also support the perception among country delegates of the need for further guidance on SIS. Only 2 of the 11 developing country respondents strongly disagree that the UNFCCC should provide further guidance on SIS. Half of the developed country

Southeast Asian Nations (ASEAN). Consequently the views of these organizations are represented twice in Annex 1.

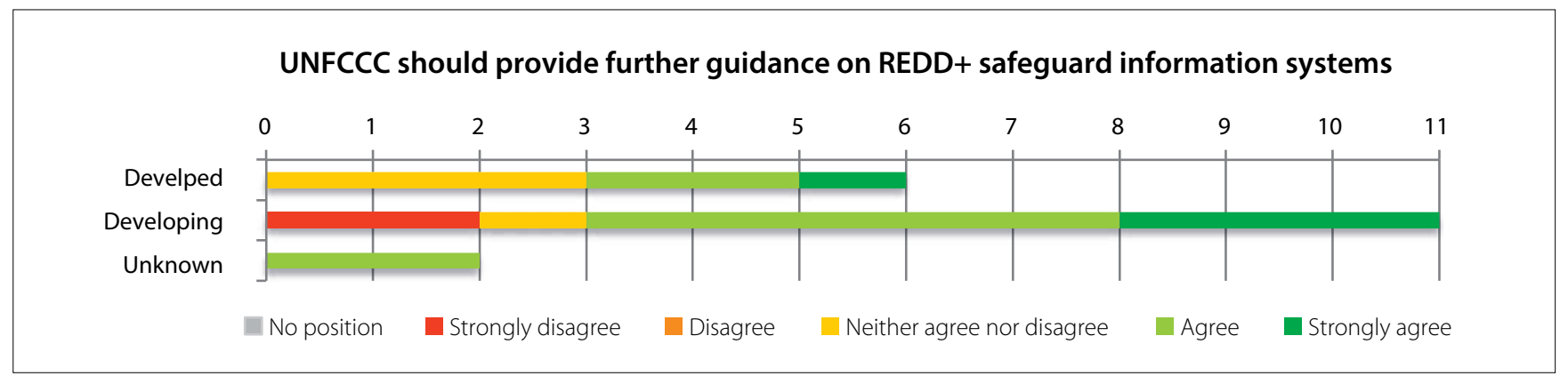

Figure 1. Delegates' online survey responses on the need for further guidance from UNFCCC (developed = developed countries; developing = developing countries; unknown = respondent did not disclose his country provenience)

Two Parties (Ecuador and Mexico) are strongly against further guidance, arguing that: "Guidance already provided in Decision 12/CP.17 and in the Warsaw Framework, as well as requirements for obtaining results-based finance, are already adequate" (Mexico submission). A third (Malaysia) focuses its submission on concerns about further guidance. Three Parties (Norway, Bolivia and the

9 The Tri-Caucus was formed in 2014 and is made up of the RSWG, the Accra Caucus and the Indigenous Peoples Caucus. respondents agree with further guidance, while the other half neither agree nor disagree. Two additional unknown respondents also agree with the need for further guidance.

\section{Reasons for and against further guidance}

In the sections that follow, we outline some of the key themes in the discourse for and against guidance. Table 2 provides a summary of these positions as identified in the submissions. 
Table 2. Summary of submissions for and against further guidance for SIS (acronyms are explained in Table 1)

\begin{tabular}{|c|c|c|c|}
\hline In favor of further guidance - Basis & $\begin{array}{l}\text { Developing } \\
\text { country }\end{array}$ & $\begin{array}{l}\text { Developed } \\
\text { country }\end{array}$ & CSO/IGO \\
\hline As a means to assess implementation of safeguards & & EU & $\begin{array}{l}\text { AIPP, Cl-led group, RECOFTC, } \\
\text { T-C, TI, WWF }\end{array}$ \\
\hline To provide feedback on the impact of REDD+ activities & & & RECOFTC, T-C, TI, WWF \\
\hline To increase equity in REDD+ implementation & Bolivia & USA & $\begin{array}{l}\text { AIPP, CAN, Cl-led group, RSWG, } \\
\text { RECOFTC, T-C, Tebtebba, TI, } \\
\text { WWF }\end{array}$ \\
\hline To increase effectiveness of safeguards implementation & $\begin{array}{l}\text { ASEAN, } \\
\text { COMIFAC }\end{array}$ & Norway, USA & $\begin{array}{l}\text { AIPP, CAN, Cl-led group, COICA, } \\
\text { IGES, REFOCTC, RSWG, T-C, TI, } \\
\text { WWF }\end{array}$ \\
\hline To increase transparency & COMIFAC & Norway & CAN, RSWG, TI, WWF \\
\hline $\begin{array}{l}\text { To simplify the burden of reporting by providing clear } \\
\text { guidance on the information and reporting requirements }\end{array}$ & COMIFAC & EU & CAN, RECOFTC, RSWG, WWF \\
\hline $\begin{array}{l}\text { To assist countries to make the most of synergies with } \\
\text { reporting for other agreements and standards }\end{array}$ & COMIFAC & EU & $\begin{array}{l}\text { CAN, Cl-led group, RSWG, } \\
\text { RECOFTC, }\end{array}$ \\
\hline $\begin{array}{l}\text { To increase opportunities for REDD+ success by reassuring } \\
\text { investors and increasing capacity }\end{array}$ & COMIFAC & Norway, USA & CAN, Cl led group, RSWG \\
\hline Against Further Guidance - Basis & $\begin{array}{l}\text { Developing } \\
\text { Country }\end{array}$ & $\begin{array}{l}\text { Developed } \\
\text { Country }\end{array}$ & CSO/IGO \\
\hline $\begin{array}{l}\text { It would compromise the need to simplify the burden of } \\
\text { reporting }\end{array}$ & Ecuador & & \\
\hline $\begin{array}{l}\text { Further guidance disregards the need for local specificity: } \\
\text { the type of information provided as evidence will depend } \\
\text { on the national circumstances and capabilities }\end{array}$ & $\begin{array}{l}\text { Ecuador, } \\
\text { Malaysia }\end{array}$ & & \\
\hline $\begin{array}{l}\text { Guidance provided in Decision } 12 / C P .17 \text { and in the Warsaw } \\
\text { Framework, and requirements for obtaining RBPs are } \\
\text { already adequate }\end{array}$ & Ecuador, Mexico & & \\
\hline
\end{tabular}

There are four main groups of positions on further guidance : (i) Parties and CSO/IGOs who argue that the current guidance is inadequate and further guidance would streamline the process and facilitate more efficient and effective SIS implementation and reporting, and thus increase financing opportunities; (ii) CSO/IGOs who support further guidance and focus almost exclusively on its role in ensuring equity and the protection of local peoples' rights and their participation in the process; (iii) REDD+ eligible countries who argue that further guidance compromises national sovereignty and countrydriven processes and will further burden the process of SIS implementation and reporting; and (iv) Parties and CSO/IGOs that address both the costs and benefits of further guidance and either do not explicitly support or oppose it, or call for further guidance that facilitates country-driven processes and lessens bureaucracy.

\section{Country-driven processes versus comparability of SIS}

The submissions give the sense of a perceived trade-off between the potential for further guidance to allow for comparability of country implementation and the risk that further guidance would compromise country-driven and nationally relevant processes. Three of the civil society submissions (T-C, RSWG and Climate Action Network, CAN) call for consistency between reporting requirements that would allow for comparability amongst countries. However, two (RSWG and WWF) also make reference to the need for flexibility to adapt SIS to national realities and capacities. The RSWG submission proposes that "additional guidance will assist countries that lack the technical and financial capacities to implement the safeguards by providing a clear and indicative structure identifying elements for their summaries of information."

The Center for People and Forests (RECOFTC) recognizes "the sovereign right of states to establish SIS appropriate for their national context and capacities." The RSWG submission asserts that "a fundamental building block of the summary of information should be an explanation of how the reporting country understands or interprets each of the safeguards according to its national context."

The Party submissions emphasize the need for nationally adapted and country-driven processes, particularly by those countries opposed to further guidance. Ecuador and Mexico express the view that the current guidance is sufficient to determine at the national level how to implement safeguards and build the SIS considering specific contexts and circumstances. According to Ecuador, "the use of a one-size-fits-all tool—or approach—for providing information on how safeguards are being addressed 

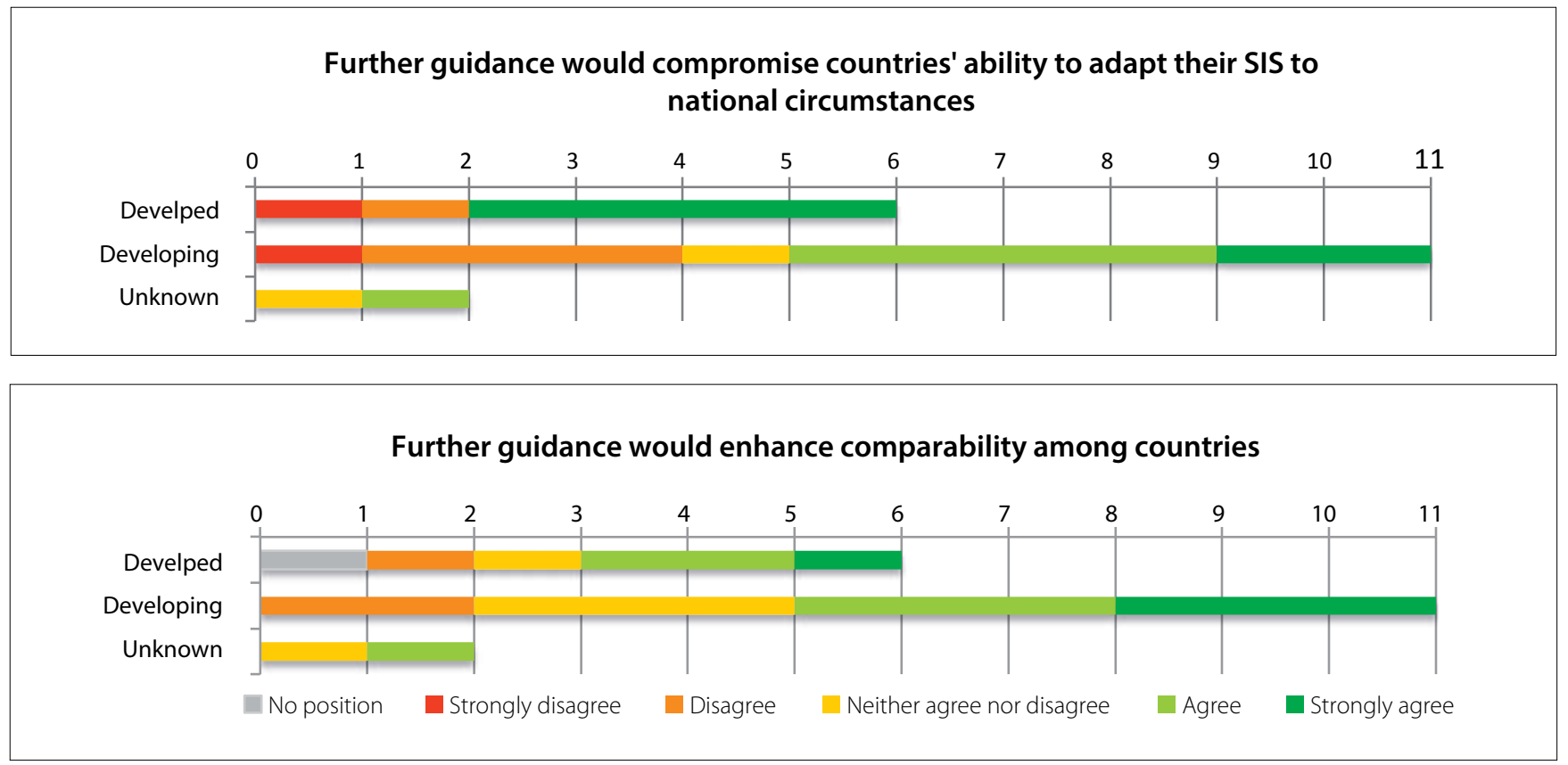

Figure 2. Delegates' online survey responses on guidance, national circumstances and comparability

and respected, presents as a significant challenge." Ecuador reiterates throughout their submission the importance of SIS being "country-driven". Malaysia, while refraining from comment on the question of whether further guidance was needed, also emphasizes that "the information provided should be country driven" and "based on the national circumstance and capabilities of a country."

As illustrated in Figure 2, most survey respondents (11) agree that further guidance would compromise countries' ability to adapt to national circumstance. Of the six that disagree, two are from developed countries and four from developing countries. On the question as to whether further guidance would enhance comparability among countries, the survey highlights that about half of respondents (10) are in agreement, five neither agree nor disagree and only three disagree.

In the open-ended response section, one developed country survey respondent states: "The purpose of reporting on how the REDD+ safeguards are being addressed and respected is not to compare countries' performance but rather as a means for a country to describe how they are doing so, and demonstrating consistency with the principle of transparency."

\section{Simplifying the reporting process}

Further guidance is outlined by some submissions as a means to simplify the reporting process, whereas others argue that it would bring additional burden. The EU notes in its submission that it is important to keep the reporting burden as low as possible to facilitate broad country participation. WWF considers "that further guidance on safeguards should be supportive of developing countries' efforts to implement REDD+, not a burden." Submissions that argue against further guidance expect that it would increase the burden of reporting and not achieve the goal of streamlining the process. Norway suggests a stepwise approach to SIS, on the consideration that developing country Parties could provide information according to their stage of REDD+ implementation.

The vast majority of survey respondents agree that further guidance would streamline the reporting process, but two developing country respondents disagree. On the question as to whether further guidance would make it easier to provide information on safeguards implementation, most respondents to the survey are in agreement, again with only two Parties in disagreement (Figure 3).

One least developed country (LDC) survey respondent states, "It would be better if countries could be supported to build the SIS using the guidance already available instead of making SIS more complicated to the extent of making [it] a REDD+ barrier."

\section{Increasing investor confidence and financing opportunities}

Some submissions argue that further guidance could increase investor confidence and thus increase access to financing opportunities. Four Party submissions, ${ }^{10}$ four CSO submissions ${ }^{11}$ and the CBD emphasize that SIS are a prerequisite for countries to receive results-based payments. Six submissions ${ }^{12}$ go further to mention the value of guidance in ensuring that strong evidence of compliance with safeguards is provided to reassure potential REDD+ investors, thereby increasing opportunities to receive REDD+ finance. Norway, one of the major REDD+ donors, argues that "being able to provide information on how these safeguards are addressed and respected will increase the confidence of

\footnotetext{
10 COMIFAC, Ecuador, Norway, USA.

11 AIPP, TI, RSWG, WWF.

12 CAN, Cl-led group, COMIFAC, Norway, RSWG, USA.
} 

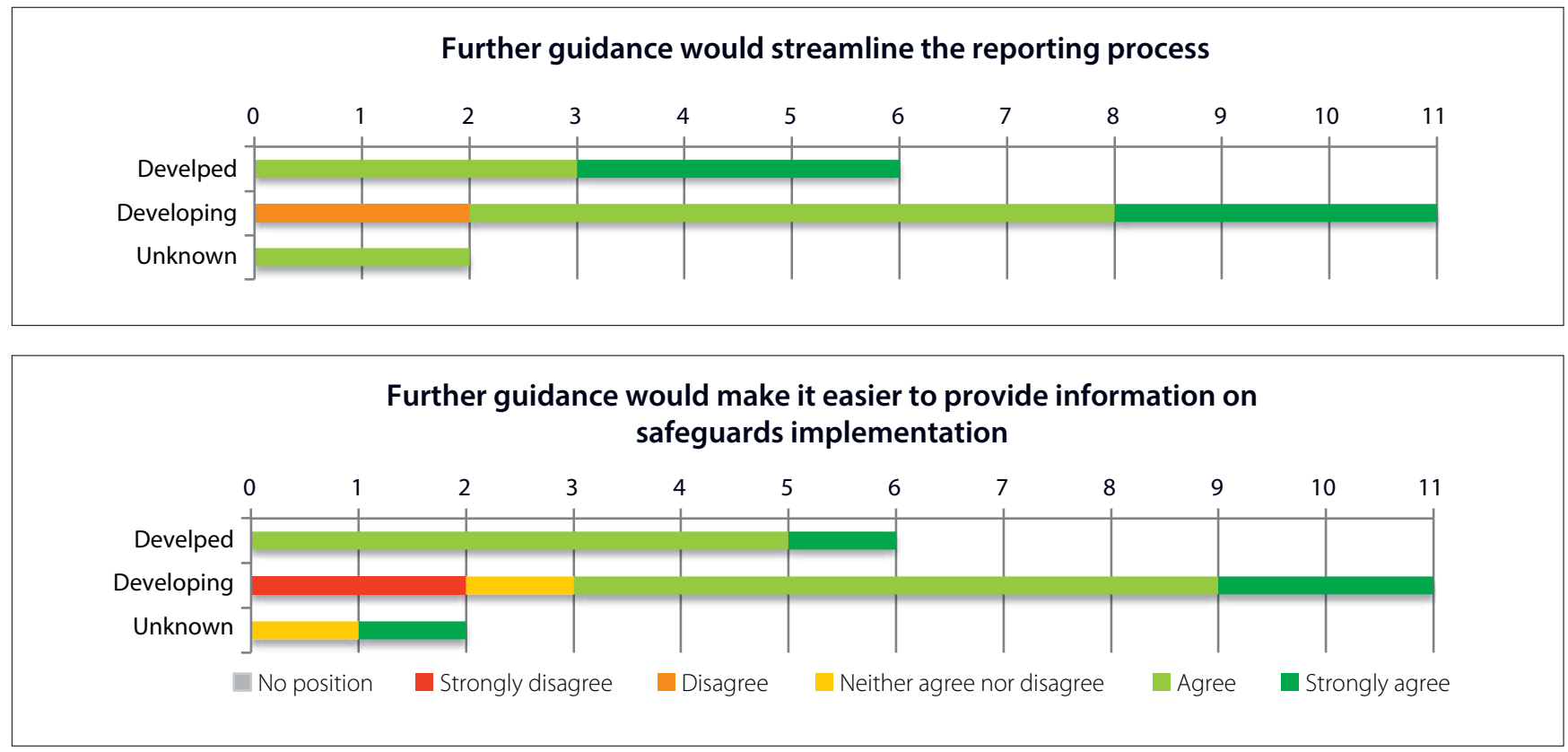

Figure 3. Delegates' online survey responses on guidance and reporting

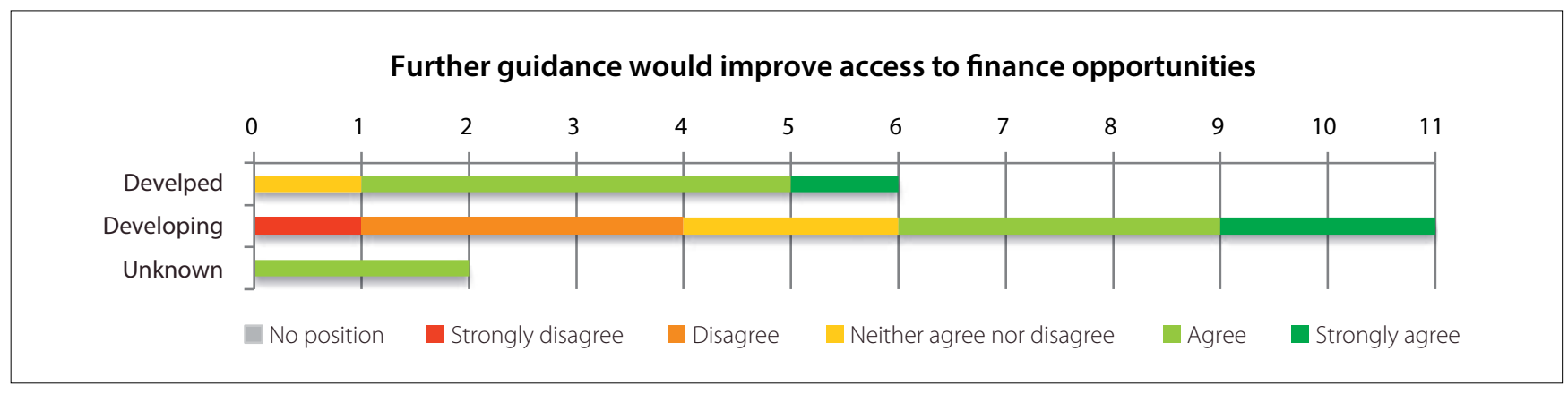

Figure 4. Delegates' online survey responses on guidance and finance

the international community in REDD+ and thereby help attract long-term investments and payments for performance." The USA makes the point that "it is likely that programs with good, quality, transparent information on safeguards will attract better funding."

Five of the developing country survey respondents agree with the assertion that further guidance would improve access to financing opportunities but four disagree. In contrast, most (five) of the developed country respondents agree (Figure 4).

\section{Alignment of REDD+ SIS with other safeguards and reporting systems}

Although the Cancun safeguards were agreed upon in 2010, the different safeguards systems that exist for REDD+ are still not aligned and some do not align fully with the Cancun safeguards (Roe et al. 2013). Six submissions ${ }^{13}$ highlight the need to reconcile the different safeguards and reporting requirements of funders and conventions. These include mention of the Cancun safeguards, World Bank safeguards and REDD+ SES, as well as

13 CAN, COMIFAC, Cl-led group, EU, RECOFTC, RSWG. reporting requirements for the Convention on International Trade in Endangered Species (CITES), the Aichi Targets of the CBD ${ }^{14}$ and the EU Forest Law Enforcement Governance and Trade (FLEGT). More recently, the GCF has agreed on interim standards that are also not aligned with the Cancun safeguards despite there now being a GCF RBP Framework in place.

It is important to note that what is classified as a safeguard under REDD+ is often equivalent or similar to social and environmental indicators in other reporting systems, and there is much overlap in the evidence countries could provide. The RSWG submission quotes an earlier statement by Ecuador that "the complex and confusing international support with multiple safeguard approaches" represents a challenge. ${ }^{15}$ The EU state that they "would be in favour of harmonising safeguard requirements and working towards developing ultimately a common framework, which would allow for the collection and harmonisation of the

14 See discussion in Miles et al. (2013).

15 Quoted by RSWG, original text from Durbin et al. (2014). 
information requirements in a simple, easily accessible and transparent manner."

For example, it is intended that the World Bank's safeguards concerning the emission reduction prograxms supported by the FCPF Carbon Fund promote and support the UNFCCC safeguards for REDD+. ${ }^{16}$ Nine countries ${ }^{17}$ have now submitted their ER-PINs to the FCPF, presenting their plans for national emission reduction programs. Parties are expected to incorporate Strategic Environmental and Social Assessment (SESA) outputs and/or outcomes into their proposed emission reduction programs. Parties should address likely gaps or issues regarding compliance of the proposed emission reduction program activities with applicable safeguard standards, including the UNFCCC safeguards.

Our analysis of the ER-PINs shows that safeguards are mentioned in all of them, and SIS in all but one. The extent to which safeguards are considered and discussed varies substantially. Five of the ER-PINs directly refer to the UNFCCC Cancun Agreement, two (Peru and Republic of the Congo), present detailed time and budget plans for safeguards and SIS, and two (Mexico and Chile) emphasize the need for safeguards and SIS to meet national and international requirements and to fit into the country's legal framework.

Respondents to the survey are divided on this subject. For developing country respondents, 9 of 11 agree that safeguards should be aligned and 2 disagree. On the other hand, only two of the developed country respondents agree, with half stating they neither agree nor disagree (Figure 5). processes, governance systems that promote transparency and protect local communities' and indigenous peoples' rights and traditional systems) or the rationale against further guidance (e.g. national sovereignty).

The CBD, nine CSOs and four of the Parties ${ }^{18}$ all highlight the importance of transparency within SIS but not specifically as a justification for further guidance. Four $\mathrm{CSOs}^{19}$ and two Parties (Norway and COMIFAC) argue that further guidance is a means to ensure transparency. According to both COMIFAC and WWF "there is no guidance on how to actually meet the SIS requirements of transparency, consistency, effectiveness and comprehensiveness."

Four Parties and ten $\mathrm{CSO} / \mathrm{IGOs}^{20}$ argue for further guidance as a means to increase the effectiveness of safeguard implementation. Seven submissions ${ }^{21}$ mention the importance of strong guidance as a means to ensure that SIS reporting works well in order to check on implementation of safeguards.

Thirteen of the submissions mention the concept of equity. ${ }^{22}$ Nine CSO/IGOs and two Parties ${ }^{23}$ mention supporting further guidance as a means to improve the equity of REDD+. Eight ${ }^{24}$ of the 11 proguidance CSO/IGO submissions emphasize local and indigenous peoples: their rights, laws and knowledge should be taken into account and they should have full participation in implementing, monitoring and reporting of safeguards and SIS. RECOFTC warns that if "key stakeholders to whom the safeguards relate are not closely involved in the design, implementation, monitoring and reporting of SIS, there is strong likelihood that such SIS will not

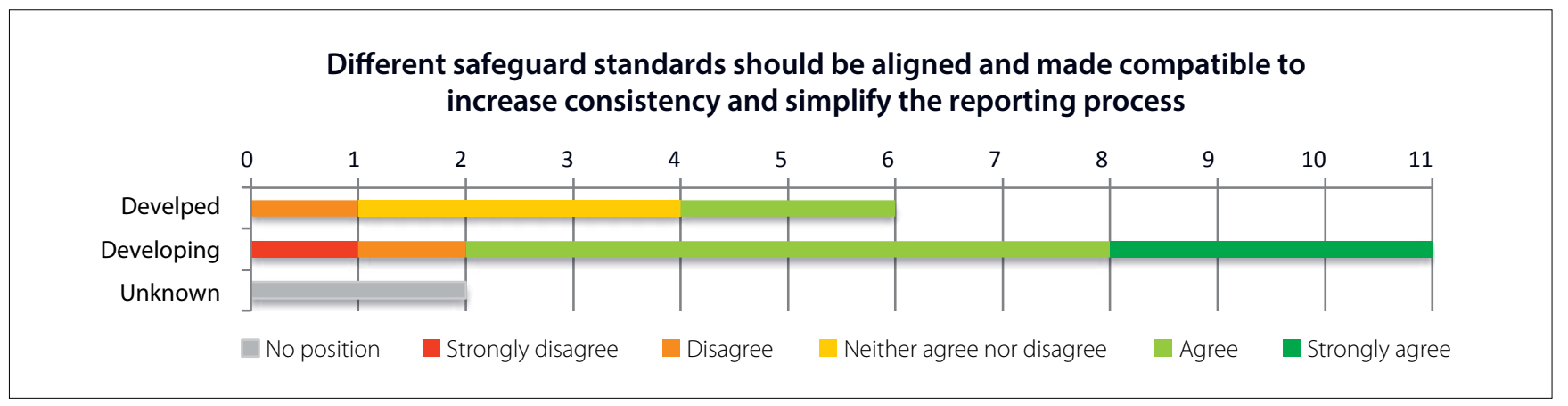

Figure 5. Delegates' online survey responses on safeguard consistency among standards

\section{Transparent, equitable and effective implementation}

The themes of transparency, equity and effectiveness, both in terms of REDD+ implementation and the SIS process itself, underpin many of the arguments put forth in the submissions. Although not emphasized directly as a rationale for further guidance in some submissions, the themes of equity, transparency and effectiveness are reflected in the discourse surrounding the types of guidance (see guidance section below) that they argue should be included (e.g. participatory

16 FCPF Facility Management Team (FMT) Note CF-2013-3.

17 Chile, Costa Rica, the Democratic Republic of the Congo, Ghana, Mexico, Nepal, Peru, the Republic of the Congo and Vietnam. be effective and will not respond to the spirit in which it was proposed."

18 AIPP, CAN, Cl-led group, COICA, the Institute for Global Environmental Strategies (IGES), RSWG, Tebtebba, TI, WWF, EU, Malaysia, Mexico and USA. 19 CAN, TI, RSWG and WWF.

20 ASEAN, COMIFAC, Norway, USA, AIPP, CAN, Cl-led group, COICA, IGES, REFOCTC, RSWG, T-C, TI, WWF.

21 AlPP, Cl-led group, EU, RECOFTC, T-C, TI, WWF.

22 AIPP, Bolivia, CAN, CBD, COICA, COMIFAC, EU, IGES, RECOFTC, RSWG, T-C, Tebtebba, WWF.

23 AIPP, CAN, CI-led group, COMIFAC, EU, RECOFTC, RSWG, T-C, Tebtebba, TI, WWF

24 AIPP, COICA, Cl-led group, IGES, RSWG, RECOFTC, Tebtebba, WWF. 


\section{Types of guidance}

While all of the submissions address the issue of further guidance in some capacity, some do not specify the types of guidance that is needed. Beyond the wider convergence on the importance of requiring local participation in the process, 18 submissions (7
Party, 11 CSO/IGO) provide some detail on what the guidance should include in terms of the specific components of the SIS. Table 3 provides a summary of the types of guidance specified throughout the submissions.

Table 3. Summary of types of guidance (abbreviations are explained in Table 1)

\begin{tabular}{|c|c|c|c|}
\hline Types of guidance & $\begin{array}{l}\text { Developing } \\
\text { country }\end{array}$ & $\begin{array}{l}\text { Developed } \\
\text { country }\end{array}$ & CSO /IGO \\
\hline \multicolumn{4}{|l|}{ What guidance should be given? } \\
\hline $\begin{array}{l}\text { How to design safeguarding and reporting processes that are } \\
\text { adapted to the national and local context }\end{array}$ & ASEAN & & RSWG, WWF \\
\hline $\begin{array}{l}\text { Outline of the types of information that should be provided as } \\
\text { evidence }\end{array}$ & Bolivia, COMIFAC & EU & RSWG \\
\hline The timing of reporting & & EU, USA & $\mathrm{T}-\mathrm{C}$ \\
\hline The frequency of reporting & & EU & RSWG, T-C \\
\hline $\begin{array}{l}\text { Guidance should help countries identify who is best placed to } \\
\text { collect information }\end{array}$ & & & RSWG, T-C, WWF \\
\hline $\begin{array}{l}\text { Guidance should emphasize the importance of participation of } \\
\text { local communities (including women and indigenous peoples) in } \\
\text { data collection }\end{array}$ & & EU & $\begin{array}{l}\text { AIPP, CI-led group, } \\
\text { RECOFTC, RSWG, T-C, } \\
\text { WWF }\end{array}$ \\
\hline $\begin{array}{l}\text { Guidance should emphasize the importance of participation of } \\
\text { Local communities in data verification }\end{array}$ & & & $\begin{array}{l}\text { AIPP, CI-led group, } \\
\text { RECOFTC, T-C, WWF }\end{array}$ \\
\hline $\begin{array}{l}\text { Consequences for lack of compliance with safeguard } \\
\text { implementation }\end{array}$ & & & AIPP, T-C \\
\hline Translation to local languages should be provided & & & AIPP, RSWG, TI, WWF \\
\hline
\end{tabular}

\section{What evidence should the guidance require?}

Political will and resources (including finance allocated) to ensure

Cl-led group, RSWG the effective implementation of safeguards

Engagement of stakeholders in the development of national $\quad$ ASEAN EU, Norway COICA, IGES, RSWG approach(es) to safeguards, including the SIS

Improved governance and addressing corruption

Evidence of a legal framework, which includes the laws, policies, regulations, plans or programs relevant to the implementation of the safeguards

Current gaps in the legal framework and plans to address those gaps identified

\section{The institutional framework}

Coordination between local, provincial, subnational and national governments

The compliance framework, which includes channels for addressing grievances, redress mechanisms and mechanisms to protect complainants and whistle-blowers, and enforcement

How forest cover is monitored and whether and how indigenous peoples and local communities have been involved in the monitoring

Biodiversity conservation and prevention of forest loss and conversion

How the SIS will be improved based on the experiences and lessons ASEAN, COMIFAC learned in the reported period

ASEAN, COMIFAC Norway, USA

AIPP, RSWG, TI,

Cl-led group, COICA, IGES, RECOFTC, RSWG, WWF IGES, RSWG
AIPP, Cl-led group, RECOFTC, RSWG

IGES, RSWG, Tebtebba AIPP, COICA, IGES, RECOFTC, RSWG, Tebtebba, TI, USA WWF

COMIFAC EU, Norway RSWG, T-C

Bolivia

EU

CBD, RSWG 


\section{Guidance on participation}

Linking back to the call for increasing transparency, equity and effectiveness of implementation, CSOs strongly emphasize the importance of local participation in both monitoring safeguard compliance and verification of the data collected, and the inclusion of groups who have historically often been excluded (e.g. indigenous people, women and rural communities). Seven submissions ${ }^{25}$ call for guidance to require local participation in data collection and five ${ }^{26}$ include verification. Four submissions call for translations to local languages. ${ }^{27}$ For three $\mathrm{CSO}^{2},{ }^{28}$ the importance of indigenous participation in the process at all levels is the central theme of their submissions. Tebtebba states, "Integral to effective mitigation and adaptation to climate change is the participation of women, especially indigenous women, whose historical contribution and roles in these areas have been recognized." The RSWG also asserts that countries should provide evidence of engagement of stakeholders in the process of developing their SIS.

RECOFTC points to community forestry and communitybased forest landscape management as an important existing framework for SIS, implementation, monitoring and reporting. AIPP states that REDD+ countries should ensure the integration of community monitoring systems while designing SIS. Further, "the effective participation of communities in generating, monitoring and validating data for SIS should be guaranteed."

Country submissions, notably that of the EU, also mention these issues but in less detail. For example the EU states: "Stakeholder involvement in the design of a country's SIS and review is of paramount importance. Moreover, involving local communities in the collection and processing of information can enhance cost-effectiveness and ownership. Independent inputs from third parties, including non-governmental actors should be encouraged."

\section{Guidance on information concerning governance}

Governance, of both REDD+ and the forest and land-use sectors, are seen as key determinants of REDD+ outcomes and national capacity to achieve REDD+ objectives. Seventeen of the submissions speak of the need to include information on governance within the SIS. These include calls for evidence of political will and resources to implement safeguards, ${ }^{29}$ efforts to improve governance and address corruption, ${ }^{30}$ and demonstration of the legal framework that is relevant to safeguard implementation. ${ }^{31}$ Gaps in the current legal framework and plans to address them were mentioned by Norway and the IGES. The need for coordination between different levels of government (national, provincial or state, local) is highlighted by the RSWG and IGES, and the RSWG also points to the need for evidence regarding the institutional framework(s).

25 AIPP, EU, Cl-led group, RECOFTC, RSWG, T-C, WWF.

26 AIPP, Cl-led group, RECOFTC, T-C, WWF.

27 AIPP, RSWG, WWF, TI.

28 AIPP, COICA and Tebtebba.

$29 \mathrm{Cl}, \mathrm{RSWG}$.

30 RSWG, TI.

31 COICA, IGES, RECOFTC, RSWG, WWF, ASEAN, COMIFAC, Malaysia, Norway.
RECOFTC states that SIS need to respect and build upon existing legal, institutional and compliance frameworks. On the other hand, submissions from WWF and the Cl-led group state that countries need to demonstrate that existing policy and legal frameworks and other ratified international agreements support implementation of safeguards and SIS. They assert that countries need to show how safeguards translate into the given country's national circumstances and priorities. Interestingly, WWF and the Cl-led group submissions say that countries need to make sure their legal or policy frameworks support implementation of safeguards and SIS, whereas most of the ER-PIN countries say that safeguards and SIS need to fit the countries' legal and policy frameworks.

AIPP focus on the importance of recognition and respect of indigenous peoples' customary laws, traditional knowledge and forest governance systems, including their own system of collective decision making and also "legal recognition, protection and implementation of the collective rights of indigenous peoples over their lands, territories and resources." In a similar vein, Tebtebba adds: "to reflect status and trends in the practice, adherence to traditional governance systems by indigenous peoples, and its relation to contemporary institutions and governance practices."

The USA, IGES and Tebtebba submissions also raise points about the need to show how traditional forest governance structures including customary tenure and usage, have been respected. These three submissions support the need to demonstrate whether land tenure and/or land rights are clearly defined and stable in REDD+ eligible areas, and what mechanisms are in place for conflict resolution when they are not. The T-C submission says, "Strengthening communities' rights over forests and effective safeguards implementation is fundamental to the success of all forest policies, including REDD+, and it depends on robust monitoring and reporting systems through the use of community-based and participatory monitoring tools and methodologies." T-C "believe that additional guidance on the SIS must recognize and respect the importance of traditional knowledge and customary governance systems."

COICA, IGES, Norway and RSWG mention the need for a compliance framework that would address grievances and protect whistle-blowers. Transparency International lists five main recommendations to enhance the transparency and the accountability of the SIS. These include reporting on: stakeholder engagement; the effectiveness of the REDD+ grievance mechanisms and anti-corruption standards and actions; increasing access to information and disclosure; and establishment of an independent review mechanism for the SIS.

\section{Linking SIS and measurement, reporting and verification (MRV)}

Five of the submissions ${ }^{32}$ address the carbon safeguards concerning permanence and leakage and the benefit of linking SIS to MRV. The WWF submission provides examples of how established carbon MRV processes are being successfully used to address safeguards.

32 CBD, COICA, Cl-led group, USA, WWF. 
Some CSOs argue for the role of communities in forest carbon monitoring: AIPP state, "Evidence-based studies have shown that community data based on their forest monitoring are as accurate as the data gathered by the trained technical experts." RECOFTC state, "There is now abundant experience that local communities can be effective forest biomass monitors delivering high quality results. It is important that carbon monitoring associated with REDD+ not be undertaken as a separate activity and be combined to the degree possible with safeguards monitoring." WWF provides the example of how a community-MRV system in Guyana "integrates information generated on the ground with information obtained at the national level, linking the national MRV system with the SIS."

Two-thirds of the developed country survey respondents and more than half of those from developing countries agreed that "further guidance would make it easier to monitor and verify REDD+ implementation more broadly," with two developing country respondents disagreeing strongly (Figure 6). In addition, five ER-PIN documents ${ }^{33}$ identify the links between carbon MRV and SIS. through various channels on how all safeguards are addressed and respected." Two submissions (EU, RSWG) call for evidence within SIS reports on how the systems will be improved based on lessons learned.

One survey respondent calls for "regular regional capacity building with strong follow up." There is strong support for the role of South-South capacity building and sharing of lessons learned (half of respondents agree that "South-South capacity building and sharing of lessons learned should dominate over UNFCCC mandates on SIS"). Only five respondents to the survey agree with the statement that "Countries have in-house capacity to deal with SIS without UNFCCC guidance," thus highlighting the need for further capacity building and sharing of lessons learned from in-country experiences (Figure 7).

\section{Conclusions and recommendations}

Although some Parties are against providing further guidance on SIS, the majority of submissions and survey respondents are in favor. The most widely supported positions are those

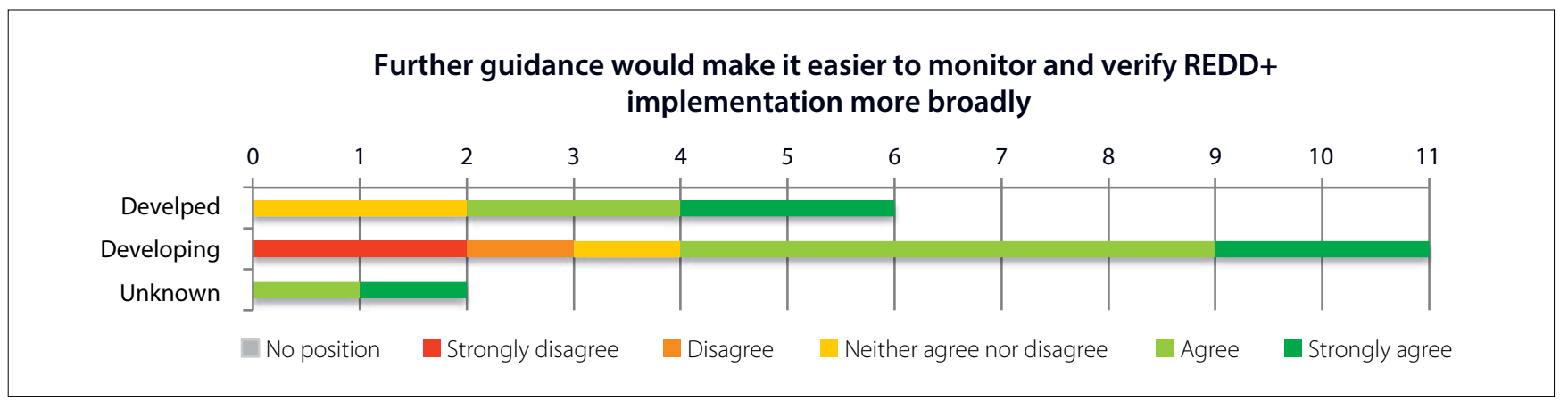

Figure 6. Delegates' online survey responses on guidance, monitoring and verification

\section{Capacity building and lessons learned}

One component of the SBSTA call for submissions asked countries to highlight challenges and lessons learned. Mexico, Bolivia, Ecuador, COMIFAC and Tebtebba all mention this but then do not provide further discussion on lessons learned. ${ }^{34}$ The $\mathrm{Cl}$-led group provides examples of in-country experiences in developing SIS and states, "Key lessons from early experiences with REDD+ show that both the process that is used and the specific types of information that are collected are critical." The RSWG includes a list of the type of information that would be useful to share in lessons-learned exchanges. WWF suggests efforts with other conventions could offer lessons and gives the biodiversity safeguards from the CBD Aichi targets as an example. ASEAN is of the view that "drawing from experiences and lessons in developing and operationalizing SIS-REDD+ are crucial in assessing transparency, consistency, comprehensiveness, and effectiveness of information provision

33 Chile, Democratic Republic of the Congo, Nepal, Peru, Republic of the Congo.

34 Several publications have addressed the issue of lessons learned from country experiences with SIS: e.g. Boyle and Murphy 2012, Durbin et al. 2013. that argue for further guidance as a means to increase the effectiveness of safeguards implementation (14 submissions) and the equity of REDD+ (11). In terms of the types of information that should be included in SIS, information on governance is the most widely requested (17 submissions). Some submissions express concern about respecting sovereignty and favor promoting country-driven approaches while minimizing the burden for creation of and reporting from SIS. Developed country Party submissions emphasize the need for SIS to demonstrate adequate governance and safeguard implementation. CSOs on the other hand, highlight issues around equity and participation of local people in the process. The contrasting views and the trade-offs presented in the submissions suggest that the most viable compromise to move the safeguarding work forward could be to produce guidance on how to develop a country-driven approach ${ }^{35}$-i.e. prioritize what is essential to include in all circumstances and present options for how to provide evidence, depending on the local situation and capacity.

35 Peskett and Todd (2013) outline recommendations for countrydriven SIS. 

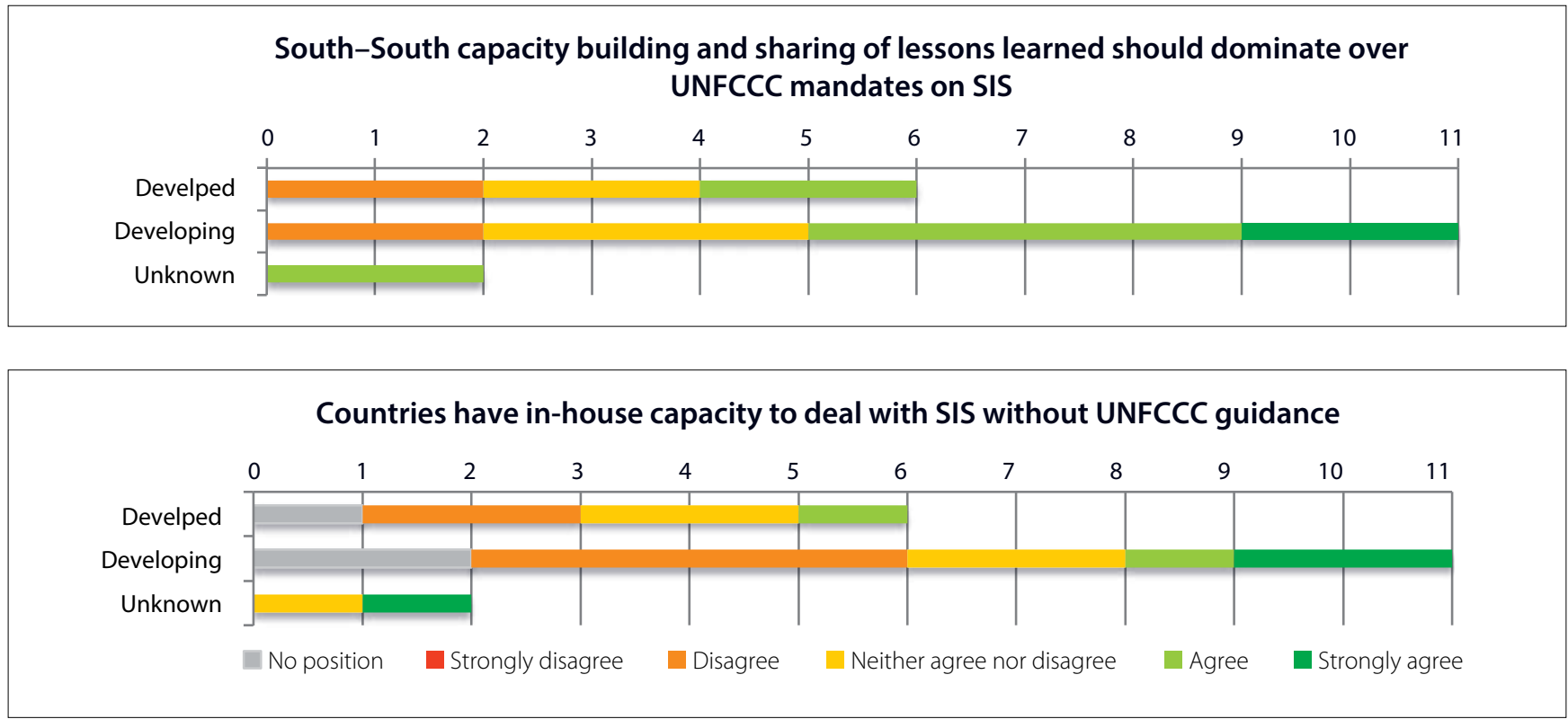

Figure 7. Delegates' online survey responses on capacity to address safeguard requirements

Norway suggests that, "Given different circumstances it is sensible for the provision of safeguards information to be approached in a stepwise manner. Developing country Parties could provide information according to their stage of REDD+ implementation, noting that the UNFCCC requires countries to provide information on safeguards throughout the implementation of REDD+ activities..." A similar tiered approach has been suggested to the CBD in the context of biodiversity safeguards under REDD+, based on capacity and availability of evidence (Gardner et al. 2012). Appropriate incentives would need to be developed to encourage Parties to improve their SIS and the lowest tier should be sufficiently rigorous and comprehensive so as to ensure adequate implementation of safeguards and reporting. Given the complex multi-level governance challenges associated with the SIS, international support for SIS development across tiers and throughout the REDD+ phases should include support for improvements across scales and sectors.

Despite some disagreements, the submissions and surveys reveal some areas of convergence surrounding key themes. REDD+ negotiators may find the following list of recommendations, based on these areas of convergence, useful during the negotiations at COP 20 in Lima:

- ensure that strong evidence of compliance with safeguards is provided to REDD+ investors, thereby increasing the potential to receive REDD+ finance;

- promote local participation in all stages of the SIS: design, data collection and verification, and revisions to the system in light of lessons learned;

- $\quad$ promote country-led processes that can adapt to national context and capacities;

- work toward an international SIS guidance framework that provides support to those countries that need and want guidance, while enabling the more advanced countries to continue moving forward;

- $\quad$ simplify the reporting process;

- $\quad$ avoid increasing the burden on REDD+ countries;
- encourage South-South sharing of lessons learned regarding SIS design and implementation;

- $\quad$ explore ways in which capacity building could strengthen country-driven SIS; and

- $\quad$ promote synergies and links between carbon MRV and SIS.

\section{Acknowledgements}

The authors gratefully acknowledge funding by the Norwegian Agency for Development Cooperation (Norad), the Australian Department of Foreign Affairs and Trade (DFAT), the European Union, the UK Government, and the CGIAR Research Program on Forests, Trees and Agroforestry (CRP-FTA) with financial support from the CGIAR Fund.

\section{References}

Boyle J and Murphy D. 2012. Designing effective REDD+ safeguard information systems: Building on existing systems and country experiences. Manitoba, Canada: International Institute for Sustainable Development (IISD).

Durbin J, Lhumeau A and Franks P. 2013. Experience supporting countries to develop safeguard information systems. REDD+ Standards Fact Sheet. REDD+SES. Accessed on 5 November 2014. http://www.redd-standards.org/files/REDD_Standards_ FactSheet_WEB.pdf

Durbin J, Lhumeau A, Franks P and Quesada A. 2014. Experiences, challenges and lessons learned about REDD+ safeguard information systems (SIS). REDD+ SES Initiative Secretariat. Accessed on 5 November 2014. http://www. unredd.net/index.php?option=com_docman\&task=doc_ download\&gid $=13211$ \&ltemid $=53$

Gardner TA, Burgess ND, Aguilar-Amuchastegui N, Barlow J, Berenguer E, Clements T, Danielsen F, Ferreira J, Foden W, Kapos V, et al. 2012. A framework for integrating biodiversity concerns into national REDD+ programmes. Biological Conservation 154:61-71. 
Jagger P, Brockhaus M, Duchelle AE, Gebara MF, Lawlor K, Resosudarmo IAP and Sunderlin WD. 2014. Multi-level policy dialogues, processes, and actions: Challenges and opportunities for national REDD+ safeguards measurement, reporting, and verification (MRV). Forests 5(9):2136-62.

Jagger P, Lawlor K, Brockhaus M, Gebara MF, Sonwa DJ and Resosudarmo IAP. 2012. REDD+ safeguards in national policy discourse and pilot projects. In Angelsen A et al., eds. Analysing $R E D D$. Bogor, Indonesia: Center for International Forestry Research.

Miles L, Trumper K, Osti M, Munroe R, Santamaria C. 2013. REDD+ and the 2020 Aichi Biodiversity Targets: Promoting synergies in international forest conservation efforts. UN-REDD Policy Brief 5. Geveva, Switzerland: United Nations Collaborative Programme on Reducing Emissions from Deforestation and Forest Degradation in Developing Countries (UN-REDD).

Peskett $L$ and Todd K. 2013. Putting REDD+ safeguards and safeguard information systems into practice. UN-REDD Policy
Brief 3. Geneva, Switzerland: United Nations Collaborative Programme on Reducing Emissions from Deforestation and Forest Degradation in Developing Countries (UN-REDD). REDD+SES. 2012. Guidelines for the use of REDD+ social and environmental standards at country level. Accessed 5 November 2014. http://www.redd-standards.org/files/pdf/ redd-docs/Standards/REDD_SES_Guidelines_Version_2_-_16_ November_2012.pdf

Roe S, Streck C, Pritchard L, Costenbader J. 2013. Safeguards in REDD+ and forest carbon standards: A review of social, environmental and procedural concepts and application. Washington DC, USA: Climate Focus

RSWG (REDD+ Safeguards Working Group). 2014. The road to Lima: REDD+ safeguards implementation and information systems. RSWG Briefing Paper. Accessed 5 November 2014. http:// reddplussafeguards.com/reddplus_safeguards/wp-content/ uploads/2014/05/R-SWG-The-Road-to-Lima.pdf

\begin{tabular}{|l|ll|}
\hline RESEARCH & $\begin{array}{l}\text { This research was carried out by CIFOR as part of the CGIAR Research Program on Forests, Trees and } \\
\text { PROGRAM ON }\end{array}$ & $\begin{array}{l}\text { Agroforestry (CRP-FTA). This collaborative program aims to enhance the management and use of } \\
\text { forests, agroforestry and tree genetic resources across the landscape from forests to farms. CIFOR }\end{array}$ \\
Forests, Trees and & $\begin{array}{l}\text { feads CRP-FTA in partnership with Bioversity International, CATIE, CIRAD, the International Center for } \\
\text { Agroforestry }\end{array}$
\end{tabular}

\section{SEED}
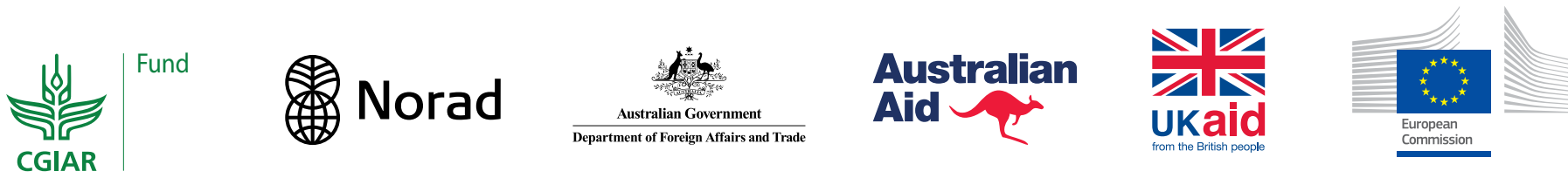